\title{
PREFACE: HEAT-MASS TRANSFER ADVANCES FOR ENERGY CONSERVATION AND POLLUTION CONTROL
}

On August 13-16, 2019, the 5th International Workshop on Heat-Mass Transfer Advances for Energy Conservation and Pollution Control (IWHT2019) was successfully held in Novosibirsk, Russia. The hosts were the Kutateladze Institute of Thermophysics and the Novosibirsk State University. The sponsors included the Kutateladze Institute of Thermophysics, Technopark of Novosibirsk Akademgorodok (Academpark), Novosibirsk State University, Russian Foundation for Basic Research, Ministry of Science and Higher Education of the Russian Federation, International Center for Heat and Mass Transfer, National Committee of Heat and Mass Transfer, and the Chinese Society of Engineering Thermophysics. The International Scientific and Advisory Committee was chaired by Prof. W.Q. Tao from the Xi'an Jiaotong University, and co-chaired by Prof. X. Zhang from the Tsinghua University and Prof. T. Simon from the University of Minnesota.

Following the same objectives as the past IWHT2011 and IWHT2013 (Xi'an), IWHT2015 (Taipei), and IWHT2017 (Las Vegas) workshops, the IWHT2019 was convened to provide an international platform for exchanging the latest technological information as well as for disseminating the high-quality research and development on heat/mass transfer problems in the areas pertinent to energy conservation and pollution control. The participants from 16 countries and areas contributed 8 plenary lectures, 28 keynote lectures, 29 invited lectures, 107 regular oral presentations, and 86 poster papers. The topics covered multiphase flow and heat/mass transfer, transport phenomena in porous media, heat/mass transfer enhancement techniques, CFD and numerical heat/mass transfer, heat exchangers, storage techniques, advanced energy systems, etc.

About $30 \%$ of the workshop papers were recommended for publication as special issues in Renewable and Sustainable Energy Reviews, Heat Transfer Research, Applied Thermal Engineering, Heat Transfer Engineering, and Journal of Physics: Conference Series. The present special issue of Heat Transfer Research includes seven high-quality papers from the workshop. The workshop organizers are grateful to Prof. Yong Tao, the Editor-in-Chief of Heat Transfer Research, for his strong support rendered to the IWHT conference series. The efforts of the authors who provided their papers for this special issue are also appreciated.

\section{Guest Editors:}

Qiu-Wang Wang

Key Laboratory of Thermo-Fluid Science and Engineering, Ministry of Education Xi'an Jiaotong University, Xi'an, P.R. China

Zhixiong Guo

Department of Mechanical and Aerospace Engineering

Rutgers, the State University of New Jersey

New Brunswick, NJ, USA

Aleksandr N. Pavlenko

Kutateladze Institute of Thermophysics

Novosibirsk, Russia

Ting Ma

Key Laboratory of Thermo-Fluid Science and Engineering, Ministry of Education Xi'an Jiaotong University

Xi'an, P.R. China 